
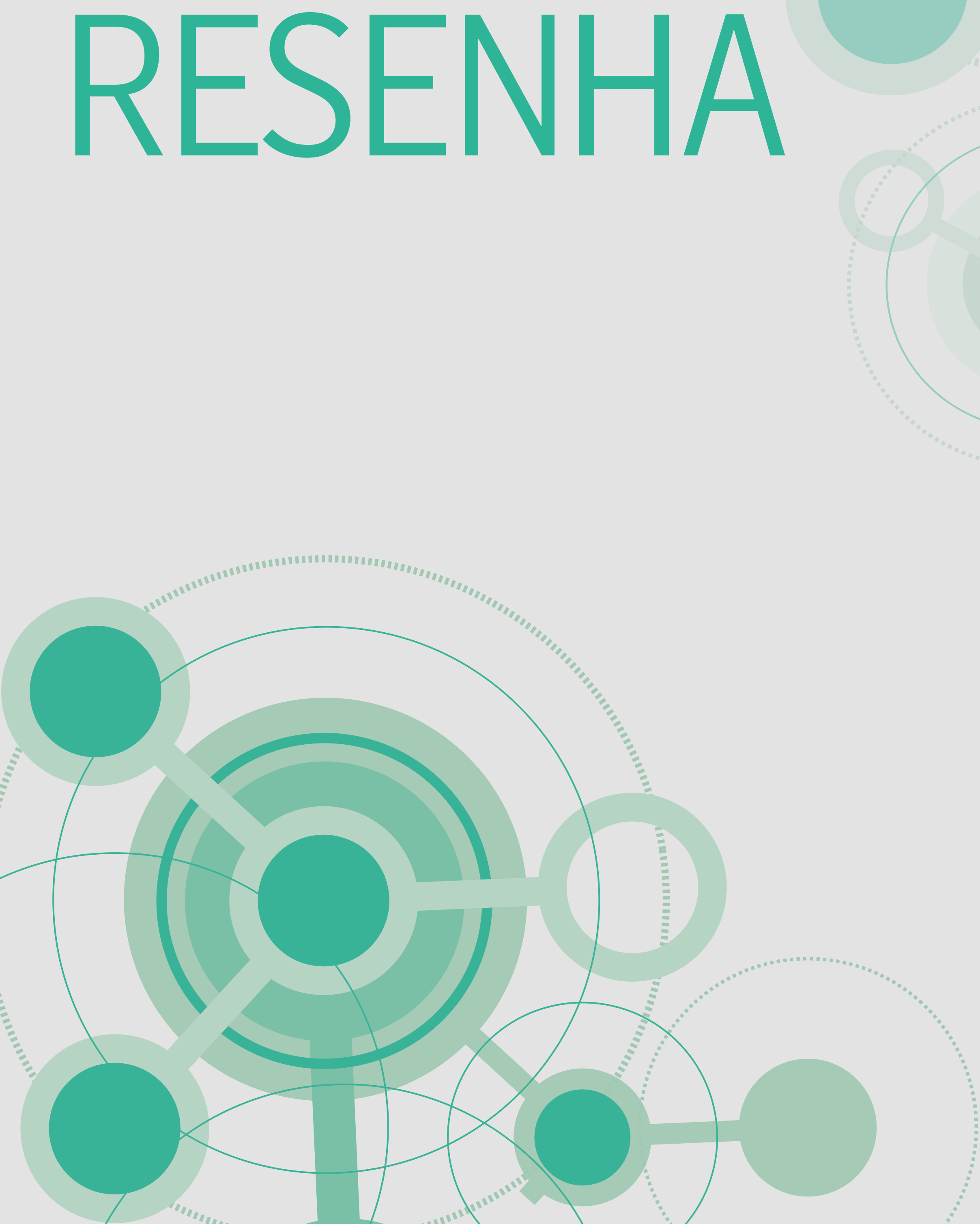


\section{Ed Catmull}

\section{CRIATIVIDADE S.A.}

SUPERANOO AS FORGAS INVISIVEIS

QUE FICAM NO CAMINHO

DA VERDADEIRA INSPIRACAO
ED CATMULL

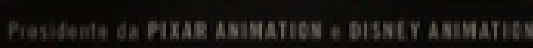

Criatividade S.A.: superando as forças invisíveis que ficam no caminho da verdadeira inspiração
Editora Rocco

Rio de Janeiro, 2014

336 páginas

\section{Camila Paschoal Bezerra}

- Discente na Escola de Comunicações e Artes da Universidade de São Paulo, no Programa de Pós-Graduação lato sensu Gestão Estratégica da Comunicação Organizacional

- Mentora na plataforma 100 Open Startups (pro bono) e membro de Harvard in Tech, grupo oficial de alumni da Universidade de Harvard para tecnologia

- Graduada em Administração Geral pela Universidade Cidade de São Paulo, com Formação Executiva em Liderança, pela Universidade de Harvard, e em Negociação, pela Universidade de Stanford, Estados Unidos

- E-mail: camilapbezerra@gmail.com 


\section{0}

\section{Um brinde aos ambientes criativos!}

\section{Hooray to creative environments!}

\section{¡Un brindis a la creatividad en ambientes laborales!}

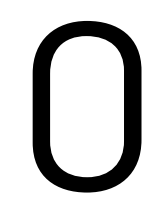

rganizada em treze capítulos distribuídos em quatro partes, a obra de Ed Catmull, cofundador da Pixar Animations Studios, apresenta a importância da cultura organizacional para o fomento da inovação e criatividade. Na Pixar, esta cultura é chamada de cultura criativa sustentável e, segundo o autor, ingrediente vital do sucesso alcançado pela companhia ao longo dos anos. Contempla os valores organizacionais, pelos quais os rituais, tradições e processos da empresa originam-se, definindo as raízes de uma filosofia que promove a resolução de problemas, estabelece a capacitação de indivíduos e grupos para a criação conjunta e permite a perpetuação de sucessos, tanto comerciais como puramente artísticos, desde a fundação da empresa, em meados dos anos 1980, até os dias atuais.

No setor inicial, "Introdução: perdido e achado", Catmull destaca como esta cultura pode ser percebida a partir, por exemplo, de rápidas e simples observações: do hall da empresa, com sede na Califórnia, contendo a irreverente escultura de quase sete metros da chamada "luminária mascote" - símbolo da empresa -, passando pelo átrio central, que contém estátuas de Buzz Lightyear e Woody, personagens principais de Toy story, primeiro longa-metragem de animação totalmente produzido em computadores em toda era do cinema, e lançado mundialmente em 1995.

Catmull destaca que a sede de mais de sessenta mil metros quadrados foi projetada, por dentro e por fora, por Steve Jobs. Menciona sua participação não apenas como sócio, mas seu papel na solidificação dos valores organizacionais da Pixar, fornecendo detalhes da colaboração do icônico criador do iPod e da equipe executiva da Pixar, relatando ainda sua liderança no desenvolvimento de parcerias entre a empresa e a Walt Disney Corporation.

Alguns exemplos das tradições existentes na empresa são também apresentados neste segmento, como o Pixarpalooza, um festival anual de bandas formadas pelos funcionários. Para Catmull, estas tradições definem o tom para que ocorra o senso de pertencer a um ambiente colaborativo e criativo. 
Na parte I, "Começando", Ed Catmull nos leva ao passado, em seus tempos de estudante de graduação, e sua posterior passagem pelo Programa de Pós-Graduação em Ciência da Computação da Universidade de Utah, onde conheceu futuros líderes da computação gráfica, tendo visto nascer a arpanet, precursora da internet, originada por um conglomerado acadêmico composto pelas Universidades da Califórnia, de Stanford, de Santa Bárbara e de Utah. Relata o desenvolvimento de seu primeiro curta-metragem animado, $A$ mão, produzido em 1972, sendo categórico ao afirmar que a comunicação foi 0 principal elemento que o permitiu alcançar tal feito.

Trabalhando em laboratórios de desenvolvimento de sistemas para criação de animações na Universidade de Utah, Catmull observou o estabelecimento de relações de confiança com outros acadêmicos, que, segundo ele, acabavam por produzir inovações tecnológicas a partir das interações uns com os outros. Estas relações de confiança, para Catmull, claramente são fruto de uma comunicação sem impedimentos, sendo vital para o alcance de objetivos.

Outra passagem, ilustrando a importância da comunicação para Catmull, encontra-se quando participa de um programa formal de intercâmbio entre a Universidade de Utah e a Walt Disney Company, que, em 1973, buscava alunos para o desenvolvimento de novas tecnologias para a animação, apresentando àquele então prodigioso aluno não apenas os arquivos dos primeiros desenhos feitos à mão pela equipe de animadores Disney, mas também a cultura de inovação da corporação fundada por Walt Disney.

Recebendo seu PhD em 1974, credita ao ambiente universitário as experiências que o formram como profissional e que iriam guiar seu comportamento enquanto executivo, além de deixar uma marca sobre a construção de ambientes ecléticos e abertos à comunicação em sua mente.

Obstinado em produzir o primeiro longa-metragem animado por computador, com um currículo de destaque, e motivado pelos desafios da época - tecnologia rudimentar, investimentos quase inexistentes no setor de animação por computador, e quase nenhum conhecimento empresarial -, Ed Catmull descreve como a aceitação do convite para assumir a posição de diretor do New York Institute of Technology, em novembro daquele ano, pavimentou seu caminho nesta empreitada e abriu portas para a gestão de equipes. A partir desta experiência, apresenta suas conclusões iniciais sobre gestão de pessoas, equipes e ambientes criativos.

A narrativa continua fornecendo detalhes sobre os resultados alcançados no instituto, e como, pouco a pouco, passou a atrair a atenção de uma indústria em desenvolvimento incipiente. Entre eles, George Lucas.

Segundo Catmull, o inventivo e relativamente jovem diretor de cinema, aos seus 32 anos, lançaria, em 1977, aquele que seria o divisor de águas na indústria do cinema moderno no que tange ao uso de tecnologia: o filme Star wars e a empresa produtora Lucasfilm.

Catmull destaca como o emergente cenário tecnológico na Califórnia, no início dos anos 1980, com o estabelecimento na região de empresas como IBM e Microsoft, e o lançamento de novos hardwares e programas de computador - como 0 surgimento e distribuição comercial do primeiro console de jogos de mesa, pela Atari - estabeleceram as bases para um mercado que hoje responde por mais de 65 bilhões de dólares em vendas globais.

Para Catmull, a Lucasfilm encaixava-se perfeitamente nesta corrida pela inovação, cercada por uma comunidade de fãs originados na intersecção entre filmes e computadores. Justamente por ser a área vislumbrada como ideal para desenvolver seus projetos em animação, decidiu aceitar uma proposta para juntar-se à companhia, assumindo uma nova divisão dedicada ao desenvolvimento de tecnologias digitais para imagens, o que o fez mudar para a Califórnia. 
A partir deste momento, iniciou os projetos de um dispositivo que pouco tempo mais tarde seria conhecido como uma unidade de negócio, a Pixar Image Computer. Com o sucesso alcançado pelo uso da tecnologia - que seria difundida por toda a indústria cinematográfica -, a Pixar Image Computer foi vendida a Steve Jobs em 1985.

Com a responsabilidade de reestruturar esta unidade, Catmull relata a criação de um novo departamento por Steve Jobs, solidificando a divisão de animações no início dos anos 1990, e firmando parcerias com o até então maior conglomerado de animações do mundo, a Walt Disney Company.

Desta forma, Catmull navega pela primeira parceria entre Disney e Pixar, contemplando a criação de três longas-metragens, e descreve dois elementos fundamentais incluídos em contrato, os quais Disney e Pixar deveriam concordar: aspectos criativos ficariam a cargo da Pixar, enquanto aspectos relacionados à distribuição comercial ficariam sob tutela da Disney. Contando com cinco anos entre desenvolvimento de roteirização e produção, Toy story foi concluído em meados dos anos 1990.

Catmull destaca ainda, como Jobs, vislumbrando a oportunidade de sucesso comercial somado à maturação financeira da Pixar, lança o IPO da empresa, abrindo seu capital na bolsa, angariando recursos necessários para que a companhia pudesse sustentar seus próximos objetivos, permitindo aos executivos da Pixar uma reestruturação no contrato com a Disney, e garantindo maior solidez à empresa.

Durante a parte II, "Protegendo o novo", Catmull descreve sua nova missão como executivo-chave da corporação e guardião de uma cultura criativa. Para ele, a cultura da Pixar deveria continuar baseada em pilares como comunicação aberta, autonomia e colaboração, pois foram estas características que permitiram que a empresa atingisse o incrível feito de ser a primeira empresa do mundo a criar um longa-metragem totalmente animado por computadores.

Para que a então chamada cultura criativa sustentável pudesse se perpetuar, recorreu à criação de projetos singulares, como o Banco de Cérebros, um board ou comitê, de caráter não hierárquico e não competitivo, que reúne-se a cada dois ou três meses para avaliar, fornecer sugestões e questionar projetos em desenvolvimento, com o único objetivo de construção coletiva. 0 comitê pode ser convocado pelo diretor do projeto e deverá reunir um fórum diverso, composto por roteiristas, desenhistas, analistas financeiros, e outros, independentemente da posição hierárquica ocupada.

Para Catmull, o board celebra a criatividade e busca novos olhares para explorações artísticas e comerciais na Pixar, apresentando-se como o espelho do ambiente universitário colaborativo e de comunicação aberta, que permitiu que seus inventos pudessem ser desenvolvidos, na Universidade de Utah.

Outro exemplo da cultura criativa sustentável na Pixar, segundo Catmull, pode ser observado através do programa Viagens de Pesquisa, sob o qual uma equipe relacionada à criação do roteiro e animação de um projeto passa por uma experiência imersiva sobre a temática em desenvolvimento. As partes II e III da obra percorrem outros modelos na empresa que celebram a cultura criativa sustentável. São os segmentos que contêm o maior número de exemplos sobre rituais e tradições da Pixar, trazendo ao leitor uma compreensão da relação entre cultura organizacional e gestão.

A parte IV narra o processo de aquisição da Pixar pela Walt Disney Company, em 2006. Além de anedotas sobre o desenvolvimento de filmes icônicos, este segmento apresenta-se como ponto alto da obra, justamente por Catmull presentear os leitores com a pedra filosofal da empresa, o santo graal da cultura organizacional da Pixar: o Compacto Social de Cinco Anos.

0 Compacto Social de Cinco Anosé um documento desenvolvido em 2006 por Steve Jobs, Catmull e outros sócios da companhia, que foi incorporado aos autos de fusão entre a Walt Disney Company e a Pixar, enumerando 59 tópicos que relatam como a 
cultura da empresa é caracterizada, oficializando os rituais em políticas de $\mathrm{RH}$ - e que deveriam ser mantidos por pelo menos cinco anos a partir da conclusão da fusão entre as duas empresas de animação.

A obra é um registro expressivo da criação e fomento da cultura organizacional da Pixar e um verdadeiro guia para todos aqueles que atuam com as temáticas criatividade, comunicação, gestão de pessoas e gestão de projetos, de estrategistas a executivos, de comunicólogos a professores e alunos, incluindo ainda os entusiastas da intersecção entre ciência e arte.

Definitivamente, uma obra que celebra a criatividade presente em cada um de nós. 